\title{
Synthesis of indolo[1,2-c]quinazolines from 2-alkynylaniline derivatives through Pd-catalyzed indole formation/cyclization with $\mathbf{N}, \mathbf{N}$-dimethylformamide dimethyl acetal
}

\author{
Antonio Arcadi ${ }^{1}$, Sandro Cacchi ${ }^{2}$, Giancarlo Fabrizi ${ }^{2}$, Francesca Ghirga ${ }^{3}$, \\ Antonella Goggiamani ${ }^{2}$, Antonia lazzetti ${ }^{*}$ and Fabio Marinelli ${ }^{* 1}$
}

\author{
Full Research Paper \\ Address: \\ ${ }^{1}$ Dipartimento di Scienze Fisiche e Chimiche, Università di L'Aquila, \\ Via Vetoio, 671010 Coppito (AQ), Italy, ${ }^{2}$ Dipartimento di Chimica e \\ Tecnologie del Farmaco, Sapienza, Università di Roma, P.le A. Moro \\ 5, 00185, Rome, Italy and ${ }^{3}$ Center for Life Nano Science@Sapienza, \\ Istituto Italiano di Tecnologia, Viale Regina Elena 291, 00161 Rome, \\ Italy

\section{Email:} \\ Antonia lazzetti ${ }^{*}$ - antonia.iazzetti@uniroma1.it; Fabio Marinelli* - \\ fabio.marinelli@univaq.it \\ ${ }^{*}$ Corresponding author \\ Keywords: \\ arylboronic acids; DMFDMA; indoles; indoloquinazolines; \\ quinazolines
}

\author{
doi:10.3762/bjoc. 14.218 \\ Received: 18 April 2018 \\ Accepted: 31 August 2018 \\ Published: 14 September 2018 \\ Associate Editor: J. Aubé
}

Beilstein J. Org. Chem. 2018, 14, 2411-2417.

(c) 2018 Arcadi et al.; licensee Beilstein-Institut. License and terms: see end of document.

\begin{abstract}
An efficient strategy for the synthesis of 6-unsubstituted indolo[1,2-c]quinazolines is described. The Pd-catalyzed reaction of $o$ - $(o-$ aminophenylethynyl) trifluoroacetanilides with $\mathrm{Ar}-\mathrm{B}(\mathrm{OH})_{2}$ afforded 2 -(o-aminophenyl)-3-arylindoles, that were converted to 12-arylindolo[1,2-c] quinazolines by adding dimethylformamide dimethyl acetal (DMFDMA) to the reaction mixture after extractive work-up. This reaction outcome is different from the previously reported Pd-catalyzed sequential reaction of the same substrates with $\mathrm{Ar}-\mathrm{I}, \mathrm{Ar}-\mathrm{Br}$ and $\mathrm{ArN}_{2}{ }^{+} \mathrm{BF}_{4}{ }^{-}$, that afforded 12-arylindolo[1,2-c] quinazolin-6(5H)-ones. Moreover, 12-unsubstituted indolo[1,2-c]quinazolines can be obtained both by reacting 2-(o-aminophenyl)indoles with DMFDMA or by sequential Pd-catalyzed reaction of $o$-(o-aminophenylethynyl)aniline with DMFDMA.
\end{abstract}

\section{Introduction}

Indoloquinazoline derivatives constitute an important class of compounds which exhibit a wide range of biological activities [1-4]. Then, extensive searches aimed at discovering pharmacologically active compounds encouraged the synthesis of some new products containing the indolequinazoline nucleus with the aim to discover novel drug candidates [5-8]. In particular, libraries of 6-substituted indolo[1,2-c] quinazolines were synthesized and exhibited good antimicrobial as well as notable antifungal activities [9-11]. Since the isolation of hinckdentine A, an unusual marine alkaloid from the bryozoan Hincksinoflustra 
denticulata collected off the eastern coast of Tasmania [12,13], indolo[1,2-c]quinazolines related to hinckdentine A received increasing attention as a source of new and useful pharmaceuticals. One well-established approach is based on the elaboration of a preformed indole ring, for example through cyclocondensation of 2-(o-aminophenyl)indoles with 2-cyanobenzothiazoles [14], aldehydes [9] and formic acid [15,16], or reactions of 2-(2-bromoaryl)- $1 H$-indoles with aldehydes and aqueous ammonia [17] or with amino acids [18]. An alternative approach to indoloquinazolines is represented by sequential procedures that use 2-alkynylaniline derivatives as starting materials, via their conversion to 2-(o-aminophenyl)indole derivatives followed by further cyclization [19-22]. Our interest in this field led to the development of an original approach to 6-trifluoromethyl-12-aryl(vinyl)indolo[1,2-c]quinazolines 4 through sequential Pd-catalyzed reactions of bis(o-trifluoroacetamidophenyl)acetylene (1) with aryl or vinyl halides and triflates followed by cyclization reactions (Scheme 1) [19].

The reaction, which tolerates a variety of important functional groups, likely involves the formation of the indole intermediates $\mathbf{2}$ (through aminopalladation/reductive elimination) [20,21] followed by cyclization to $\mathbf{3}$ and elimination of trifluoroacetic acid (Scheme 1). Later, a procedure that allows the introduction of a variety of substituents other than $\mathrm{CF}_{3}$ in the 6-position (without the substituent in the 12-position) was reported by Wang and co-workers [22]. More recently, we showed that the Pd-catalyzed reaction of $o$-(o-aminophenylethynyl) trifluoroacetanilides 5 with aryl halides and aryldiazonium salts led to the formation of 12-arylindolo[1,2-c] quinazolin-6(5H)-ones 8 in moderate to excellent yields (Scheme 2a) [23]. Very likely, under these reaction conditions, the palladium-catalyzed reaction of $\mathbf{5}$ gave intermediates $\mathbf{6}$; then, cyclization to $\mathbf{7}$ followed by elimination of trifluoromethane afforded products $\mathbf{8}$.

Since the unique molecular skeleton of hinckdentine $\mathrm{A}$ is constituted of a 6 -unsubstituted indolo[1,2-c]quinazoline nucleus [12,13], we planned to modify our previous procedures to address the 6-unsubstituted-12-arylindolo[1,2-c] quinazolines 10. We wish to report here that, under suitable reaction conditions, substrates $\mathbf{5}$ can be easily converted into target products 10 (Scheme 2b). Moreover, 12-unsubstituted analogues $\mathbf{1 3}$ are also available from $\mathbf{5}$ or from $o$-(o-aminophenylethynyl)anilines 15 (see below).

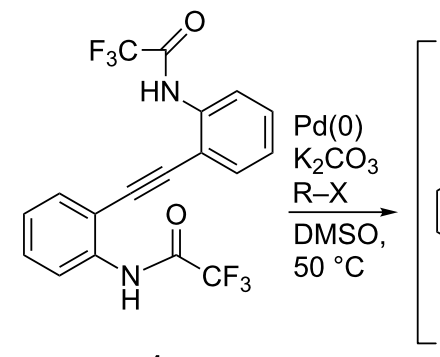

1<smiles>[R]c1c(-c2ccccc2NC(=O)C(F)(F)F)n(C(=O)C(F)(F)F)c2ccccc12</smiles>

2

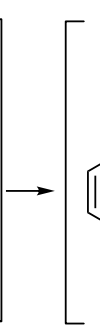<smiles>[R]c1c2n(c3ccccc13)C(O)(C(F)(F)F)N(C(=O)OCC)c1ccccc1-2</smiles>

3

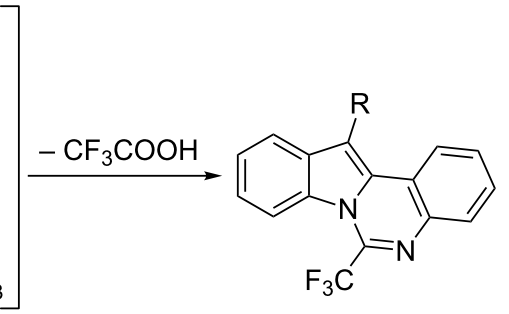

4

Scheme 1: Synthesis of 6-trifluoromethyl-12-aryl(vinyl)indolo[1,2-c]quinazolines 4.

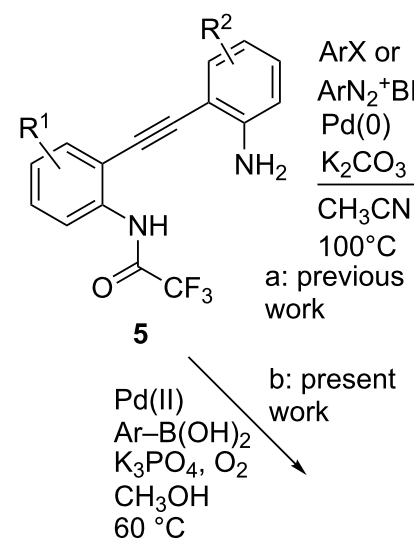

$60{ }^{\circ} \mathrm{C}$

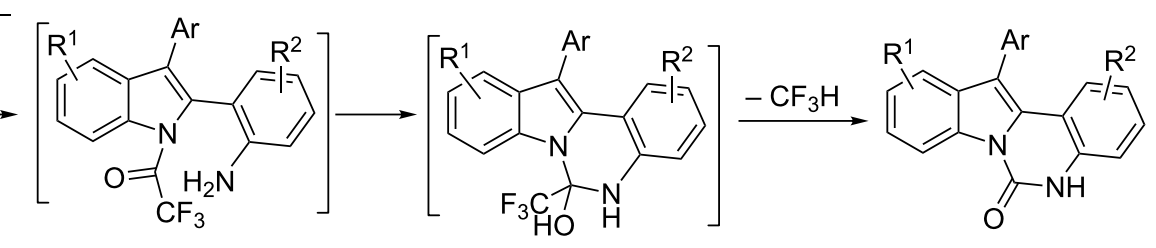

6

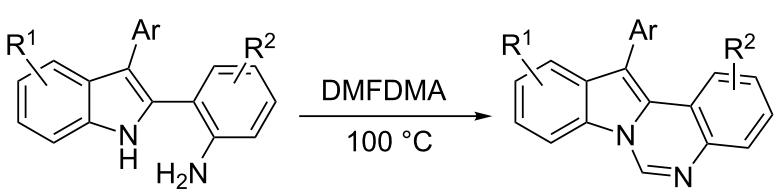

10 


\section{Results and Discussion}

We have previously reported that arylboronic acids $\mathbf{1 2}$ can be used in place of aryl halides in the Pd-catalyzed synthesis of indoles through aminopalladation/reductive elimination reaction from 2-alkynyltrifluoroacetanilides [24]. This reaction is carried out in $\mathrm{MeOH}$ at $60{ }^{\circ} \mathrm{C}$ in the presence of $\mathrm{K}_{3} \mathrm{PO}_{4}$ under an oxygen atmosphere. We then decided to react substrate $\mathbf{5}$ under these reaction conditions, in order to ascertain if the presence of methanol and base would result in the cleavage of the trifluoroacetylamide group after the formation of the indole ring, affording 2-(1H-indolo-2-yl)benzenamine derivatives 9 instead of products $\mathbf{8}$. We were pleased to observe the formation of 9a in good yields when $\mathbf{5}$ was reacted with 4-methoxyphenylboronic acid. A minor amount of product 11a (likely deriving from a transamidation reaction [25] of initially formed intermediate 6a) was also isolated. Then, 9a was treated with dimethylformamide dimethyl acetal (DMFDMA) as a source of an electrophilic one-carbon unit at the formate oxidation level [26,27], affording 12-arylindolo[1,2-c]quinazoline 10a in good yield (Scheme 3).

Based on this result, we tested an approach to target products $\mathbf{1 0}$ avoiding the isolation of intermediates 9. After some experimentation, we found that the best results were obtained from the following procedure: 1) Pd-catalyzed reaction of 5 with $\mathrm{ArB}(\mathrm{OH})_{2} / \mathrm{K}_{3} \mathrm{PO}_{4}$ in $\mathrm{MeOH}$ at $60{ }^{\circ} \mathrm{C} ; 2$ ) heating of the reaction mixture at $100{ }^{\circ} \mathrm{C}$ to allow complete hydrolysis of byproducts $11 ; 3$ ) after extractive work-up, treatment of the crude reaction mixture with an excess of DMFDMA (5 equiv) [28] in
DMF at $100{ }^{\circ} \mathrm{C}$ to obtain indoloquinazolines 10 . The results of this procedure, starting from a variety of $o$-(o-aminophenylethynyl)trifluoroacetanilides $\mathbf{5}$ and arylboronic acids 12, are summarized in Table 1.

In some cases, 12-unsubstituted indolo[1,2-c] quinazoline derivatives 13 were also obtained as byproducts. Electron-rich arylboronic acids worked quite well (Table 1, entries 1, 3, and 4). However, an attempt to carry out the reaction under air, instead of under $\mathrm{O}_{2}$ atmosphere, resulted in a loss of efficiency (Table 1, entry 2). Good results were also observed with phenyl- and 1-naphthylboronic acids (Table 1, entries 5 and 6). Electron-poor arylboronic acids proved to be effective (Table 1, entries 7-10), and only (4-chlorophenyl)boronic acid gave a moderate yield of product (Table 1, entry 10).

Products substituted in the indole and quinazoline frameworks were also obtained (Table 1, entries 12-16). It is worth noting that the reaction tolerates a $-\mathrm{Br}$ substituent (Table 1, entries 8 and 16) which may serve as a useful handle for increasing molecular complexity through cross-coupling reactions. Only in the case of two ortho-substituents on the aryl residue of the boronic acid the reaction afforded the target product 10p in low yield (Table 1, entry 17), and 12-unsubstituted derivative 13p as the major product.

Then, with the aim of obtaining 12-unsubstituted indoloquinazolines 13 selectively, we tested the use of DMFDMA for the cyclization of 2-(o-aminophenyl)indoles 14 . This reaction re-

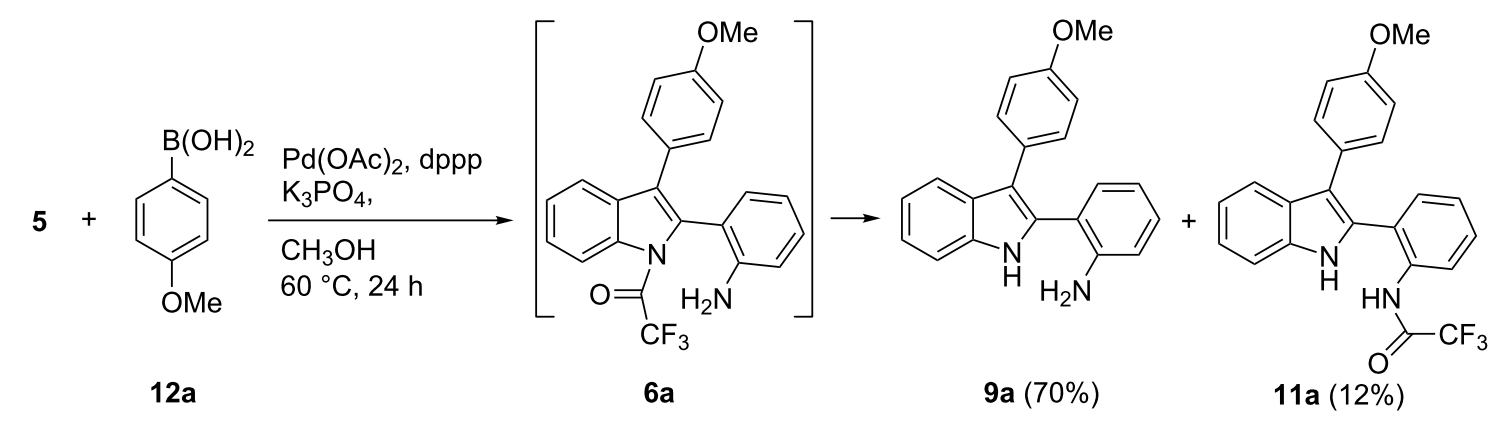<smiles>COc1ccc(-c2c3ccccc3n3cnc4ccccc4c23)cc1</smiles> 
Table 1: Synthesis of 12-arylindolo[1,2-c]quinazolines $10{ }^{a}$<smiles>[R1]OC(=O)Nc1ccc([R])cc1C#Cc1cc(P)ccc1N</smiles>

5
1. $\mathrm{Ar}-\mathrm{B}(\mathrm{OH})_{2} 12$

$\mathrm{Pd}(\mathrm{OAc})_{2}, \mathrm{dppp}$

$2 \quad \mathrm{~K}_{3} \mathrm{PO}_{4}$

$\mathrm{O}_{2}, 1 \mathrm{~atm}$

$\mathrm{MeOH}$

$60{ }^{\circ} \mathrm{C}$

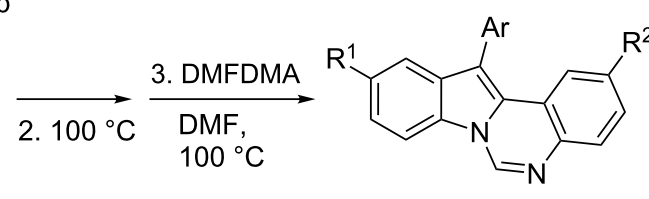

10<smiles>[Z17]c1ccc2c(c1)cc1c3cc([R])ccc3ncn21</smiles>

13

\begin{tabular}{|c|c|c|c|c|c|c|c|}
\hline Entry & $\mathrm{R}^{1}$ & $\mathrm{R}^{2}$ & 5 & $\mathrm{Ar}$ & Time $(h)^{b}$ & $10(\% \text { yield })^{c}$ & $13(\% \text { yield })^{c}$ \\
\hline 1 & $\mathrm{H}$ & $\mathrm{H}$ & $5 a$ & $4-\mathrm{MeO}-\mathrm{C}_{6} \mathrm{H}_{4-}^{-}$ & $3,16,16$ & $10 a(76)$ & - \\
\hline 2 & $\mathrm{H}$ & $\mathrm{H}$ & $5 a$ & 4-MeO- $\mathrm{C}_{6} \mathrm{H}_{4^{-}}$ & $24,18,16$ & $10 a(49)^{d}$ & - \\
\hline 3 & $\mathrm{H}$ & $\mathrm{H}$ & $5 a$ & 4-Me- $\mathrm{C}_{6} \mathrm{H}_{4^{-}}$ & $5,16,16$ & $10 b(61)$ & - \\
\hline 4 & $\mathrm{H}$ & $\mathrm{H}$ & $5 a$ & 2-Me- $\mathrm{C}_{6} \mathrm{H}_{4}-$ & $5,16,16$ & $10 \mathrm{j}(56)$ & 13j (11) \\
\hline 5 & $\mathrm{H}$ & $\mathrm{H}$ & $5 a$ & phenyl & $24,8,12$ & $10 c(75)$ & - \\
\hline 6 & $\mathrm{H}$ & $\mathrm{H}$ & $5 a$ & 1-naphthyl & $2,16,2$ & $10 d(60)$ & - \\
\hline 7 & $\mathrm{H}$ & $\mathrm{H}$ & $5 a$ & $4-\mathrm{CF}_{3}-\mathrm{C}_{6} \mathrm{H}_{4^{-}}$ & $4,7,16$ & 10 e (69) & - \\
\hline 8 & $\mathrm{H}$ & $\mathrm{H}$ & $5 a$ & $4-\mathrm{Br}-\mathrm{C}_{6} \mathrm{H}_{4-}^{-}$ & $2,16,6$ & $10 f(60)$ & - \\
\hline 9 & $\mathrm{H}$ & $\mathrm{H}$ & $5 a$ & $4-\mathrm{MeO}_{2} \mathrm{C}-\mathrm{C}_{6} \mathrm{H}_{4-}$ & $3,28,2$ & $\log (59)$ & - \\
\hline 10 & $\mathrm{H}$ & $\mathrm{H}$ & $5 a$ & 4-Cl- ${ }_{6} \mathrm{H}_{4-}^{-}$ & $6,16,3$ & $10 \mathrm{~h}(52)$ & $13 \mathrm{~h}(12)$ \\
\hline 11 & $\mathrm{H}$ & $\mathrm{H}$ & $5 a$ & & $18,16,2$ & $10 \mathbf{i}(65)$ & $13 \mathbf{i}(12)$ \\
\hline 12 & $\mathrm{Me}$ & $\mathrm{H}$ & $5 b$ & 4-MeO- ${ }_{6} \mathrm{H}_{4-}$ & $18,6,1$ & $10 k(63)$ & $13 k(5)$ \\
\hline 13 & $\mathrm{Me}$ & $\mathrm{H}$ & $5 b$ & phenyl & $24,5,4$ & $101(72)$ & - \\
\hline 14 & $\mathrm{Me}$ & $\mathrm{H}$ & $5 b$ & & $1,16,8$ & $10 \mathrm{~m}(76)$ & - \\
\hline 15 & $\mathrm{Me}$ & coOMe & $5 c$ & 4-MeO- $\mathrm{C}_{6} \mathrm{H}_{4^{-}}$ & $5,16,3$ & $10 \mathrm{n}(60)$ & - \\
\hline 16 & $\mathrm{H}$ & $\mathrm{Me}$ & $5 d$ & $4-\mathrm{Br}-\mathrm{C}_{6} \mathrm{H}_{4-}$ & $6,16,1.5$ & $100(58)$ & - \\
\hline 17 & $\mathrm{H}$ & $\mathrm{H}$ & $5 a$ & & $24,24,8$ & $10 p(12)$ & $13 p(38)$ \\
\hline
\end{tabular}

aReactions were carried out at $60^{\circ} \mathrm{C}$ on $0.345 \mathrm{mmol}$ scale using 1.0 equiv of $5,2.0$ equiv of $13,0.05$ equiv of $\mathrm{Pd}(\mathrm{OAc})_{2}, 0.05$ equiv of dppp and 2 equiv of $\mathrm{K}_{3} \mathrm{PO}_{4}$ in $\mathrm{MeOH}(2 \mathrm{~mL})$ under an atmosphere of $\mathrm{O}_{2}$; then $100{ }^{\circ} \mathrm{C}$; work-up; then 5 equiv of DMFDMA in DMF $(2 \mathrm{~mL}), 100{ }^{\circ} \mathrm{C}$. ${ }^{b} \mathrm{Numbers}$ refer to the $1 \mathrm{st}$, 2 nd and $3 \mathrm{rd}$ step, respectively. ${ }^{\mathrm{C}}$ Isolated yields. ${ }^{\mathrm{d}}$ Carried out under air atmosphere.

quired only a slight excess of DMFDMA (1.2 equiv), and afforded derivatives $\mathbf{1 3}$ as sole products in high yields (Table 2).

As described in Supporting Information File 1, indoles 14a-c $\left(\mathrm{R}^{1}=\mathrm{R}^{3}, \mathrm{R}^{2}=\mathrm{H}\right)$ were obtained by cyclization of the corresponding $o$-(o-aminophenylethynyl)anilines $15 \mathbf{a}-\mathbf{c}$ with $\mathrm{PdCl}_{2}(\mathrm{MeCN})_{2}[29,30]$. Indoles $\mathbf{1 4 d}, \mathbf{e}\left(\mathrm{R}^{1} \neq \mathrm{R}^{3}\right)$ could not be obtained in such way (due to the lack of selectivity between the two different $\mathrm{NH}_{2}$ groups in the hydroamination reaction), and were obtained by cyclization of the corresponding $o$ - $(o$-aminophenylethynyl) trifluoroacetanilides 5 with $\mathrm{PdCl}_{2}(\mathrm{MeCN})_{2}$ (it was previously demonstrated that the selective formation of $\mathbf{1 6}$ occurs under these conditions [31]) followed by the hydrolysis of the $\mathrm{COCF}_{3}$ group of the crude product (Scheme 4).

Moreover, the palladium-catalyzed reaction of $\mathbf{1 5 a}$ in the presence of DMFDMA led directly to the formation of quinazoline 13a in $71 \%$ yield through a sequential process (Scheme $5 \mathrm{a}$ ).

The selective formation of products $\mathbf{1 3}$ from $\mathbf{1 5}$ (and also from 3 -unsubstituted indoles 14) is not trivial, since the previously reported gold-catalyzed reaction of $\mathbf{1 5 a}$ with aldehydes as electrophiles resulted in the divergent formation of $11 H$-indolo[3,2- 
Table 2: Synthesis of 12-unsubstituted indolo[1,2-c]-quinazolines $13 .^{a}$<smiles>[R]c1ccc(N)c(-c2cc3cc([R])cc([R])c3[nH]2)c1</smiles>

14<smiles>[R]c1cc([R2])c2c(c1)cc1c3cc([R])ccc3ncn12</smiles>

13

\begin{tabular}{|c|c|c|c|c|c|c|}
\hline Entry & $\mathrm{R}^{1}$ & $\mathrm{R}^{2}$ & $\mathrm{R}^{3}$ & 14 & Time (h) & $13(\% \text { yield })^{b}$ \\
\hline 1 & $\mathrm{H}$ & $\mathrm{H}$ & $\mathrm{H}$ & $14 a$ & 5 & 13a (86) \\
\hline 2 & $\mathrm{Me}$ & $\mathrm{H}$ & $\mathrm{Me}$ & $14 b$ & 24 & $13 b(87)$ \\
\hline 3 & coOMe & $\mathrm{H}$ & coOMe & $14 c$ & 6 & $13 c(81)$ \\
\hline 4 & $\mathrm{H}$ & $\mathrm{H}$ & $\mathrm{Me}$ & $14 d$ & 25 & 13d (95) \\
\hline 5 & $\mathrm{Me}$ & $\mathrm{Me}$ & $\mathrm{H}$ & $14 e$ & 24 & $13 e(73)$ \\
\hline
\end{tabular}

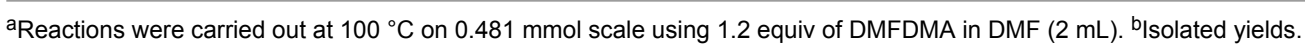

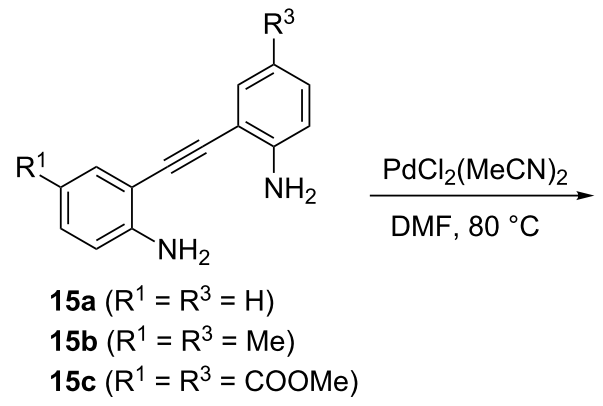<smiles>[R]c1ccc(N)c(-c2cc3cc([R])ccc3[nH]2)c1</smiles>

14a-c<smiles>[R]c1ccc(NC(=O)C(F)(F)F)c(C#Cc2cc([R])cc([R])c2N)c1</smiles>

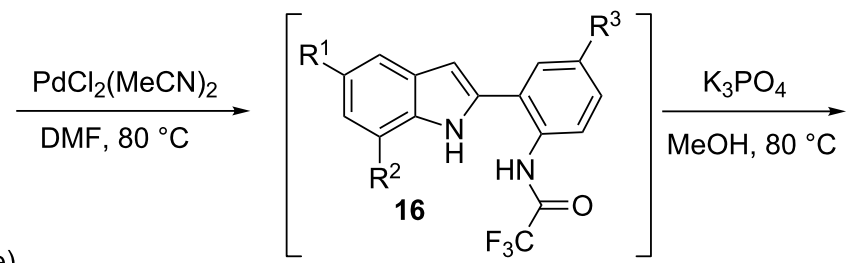<smiles>[R]c1ccc(N)c(-c2cc3cc([R])cc([R])c3[nH]2)c1</smiles>

$5 \mathbf{b}\left(R^{1}, R^{2}=H ; R^{3}=M e\right)$

$5 e\left(R^{1}, R^{2}=M e ; R^{3}=H\right)$

Scheme 4: Synthesis of indoles 14.<smiles>Nc1ccccc1C#Cc1ccccc1N</smiles>

DMFDMA (2 equiv) $\mathrm{PdCl}_{2}(\mathrm{MeCN})_{2} 5 \%$ $\mathrm{NH}_{2} \overrightarrow{\mathrm{DMF}, 100^{\circ} \mathrm{C}, 24 \mathrm{~h}}$ a) present work

$15 a$

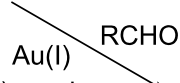
b) previous work

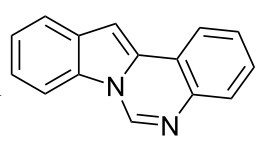

13a $(71 \%)$<smiles>[R]c1nc2ccccc2c2[nH]c3ccccc3c12</smiles>

17 c] quinolines 17 (Scheme 5b) [32] through functionalization of $\mathrm{C}-3$ position of the indole ring instead of $\mathrm{N}-1$.

The sequential reaction shown in Scheme 5, path a, probably occurs through cyclization of $\mathbf{1 5 a}$ to indole $\mathbf{1 4 a}$, followed by the reaction with DMFDMA; however, an alternative path in which one amino group interact with DMFDMA to give a formamidine intermediate [27] before cyclization cannot be ruled out.

\section{Conclusion}

We have reported here an efficient procedure for the preparation of 12-arylindolo[1,2-c]quinazolines $\mathbf{1 0}$ from $o$-(o-amino- 
phenylethynyl) trifluoroacetanilides $\mathbf{5}$ and arylboronic acids, by avoiding the isolation of intermediate indoles 9 . Starting from indoles 14, or from $o$-(o-aminophenylethynyl)aniline 15a, selective formation of 12-unsubstituted[1,2-c] quinazolines $\mathbf{1 3}$ was accomplished, without competitive formation of products derived from $\mathrm{C}-3$ functionalization at the indole moiety.

\section{Supporting Information}

\section{Supporting Information File 1}

Experimental procedures, characterization data and copies of NMR spectra.

[https://www.beilstein-journals.org/bjoc/content/ supplementary/1860-5397-14-218-S1.pdf]

\section{Acknowledgements}

We gratefully acknowledge the University of L'Aquila and the Sapienza, University of Rome, for financial support.

\section{ORCID ${ }^{\circledR}$ iDs}

Antonio Arcadi - https://orcid.org/0000-0001-9053-648X Francesca Ghirga - https://orcid.org/0000-0002-5591-5190 Antonia lazzetti - https://orcid.org/0000-0002-7792-774X

\section{References}

1. Demeunynck, M.; Baussanne, I. Curr. Med. Chem. 2013, 20, 794-814. doi:10.2174/0929867311320060006

2. Tucker, A. M.; Grundt, P. ARKIVOC 2012, No. i, 546-569.

3. Adams, M.; Mahringer, A.; Kunert, O.; Fricker, G.; Efferth, T.; Bauer, R. Planta Med. 2007, 73, 1554-1557. doi:10.1055/s-2007-993743

4. Hochfellner, C.; Evangelopoulos, D.; Zloh, M.; Wube, A.; Guzman, J. D.; McHugh, T. D.; Kunert, O.; Bhakta, S.; Bucar, F. J. Appl. Microbiol. 2015, 118, 864-872. doi:10.1111/jam.12753

5. Vaidya, S. D.; Argade, N. P. Org. Lett. 2013, 15, 4006-4009. doi:10.1021/ol4018062

6. Wang, C.; Zhang, L.; Ren, A.; Lu, P.; Wang, Y. Org. Lett. 2013, 15, 2982-2985. doi:10.1021/ol401144m

7. Nelson, A. C.; Kalinowski, E. S.; Jacobson, T. L.; Grundt, P. Tetrahedron Lett. 2013, 54, 6804-6806. doi:10.1016/j.tetlet.2013.09.124

8. Sharma, V. M.; Prasanna, P.; Seshu, K. V. A.; Renuka, B.; Rao, C. V. L.; Kumar, G. S.; Narasimhulu, C. P.; Babu, P. A.; Puranik, R. C.; Subramanyam, D.; Venkateswarlu, A.; Rajagopal, S.; Kumar, K. B. S.; Rao, C. S.; Mamidi, N. V. S. R.; Deevi, D. S.; Ajaykumar, R.; Rajagopalan, R. Bioorg. Med. Chem. Lett. 2002, 12, 2303-2307. doi:10.1016/S0960-894X(02)00431-6

9. Rohini, R.; Reddy, P. M.; Shanker, K.; Hu, A.; Ravinder, V. Eur. J. Med. Chem. 2010, 45, 1200-1205. doi:10.1016/j.ejmech.2009.11.038

10. Rohini, R.; Reddy, P. M.; Shanker, K.; Hu, A.; Ravinder, V. J. Braz. Chem. Soc. 2010, 21, 897-904. doi:10.1590/S0103-50532010000500018

11. Rohini, R.; Shanker, K.; Reddy, P. M.; Sekhar, V. C.; Ravinder, V. Arch. Pharm. 2009, 342, 533-540. doi:10.1002/ardp.200900068
12. Blackman, A. J.; Hambley, T. W.; Picker, K.; Taylor, W. C.; Thirasasana, N. Tetrahedron Lett. 1987, 28, 5561-5562. doi:10.1016/S0040-4039(00)96781-9

13. Douki, K.; Ono, H.; Taniguchi, T.; Shimokawa, J.; Kitamura, M.; Fukuyama, T. J. Am. Chem. Soc. 2016, 138, 14578-14581. doi:10.1021/jacs.6b10237

14. Frère, S.; Thiéry, V.; Bailly, C.; Besson, T. Tetrahedron 2003, 59, 773-779. doi:10.1016/S0040-4020(02)01593-4

15. Billimoria, A. D.; Cava, M. P. J. Org. Chem. 1994, 59, 6777-6782. doi:10.1021/jo00101a043

16. Dai, X.; Liu, H.; Palani, A.; He, S.; Lai, Z.; Nargund, R.; Marcantonio, K.; Xiao, D.; Brockunier, L. L.; Zorn, N.; Dang, Q.; Peng, X.; Li, P. Tetracyclic heterocycle compounds and methods of use thereof for the treatment of hepatitis c. WO Patent WO2014/123794A1, Aug 14, 2014.

17. Guo, S.; Tao, L.; Zhang, W.; Zhang, X.; Fan, X. J. Org. Chem. 2015, 80, 10955-10964. doi:10.1021/acs.joc.5b02076

18. Liu, Q.; Yang, H.; Jiang, Y.; Zhao, Y.; Fu, H. RSC Adv. 2013, 3, 15636-15644. doi:10.1039/c3ra41644e

19. Arcadi, A.; Cacchi, S.; Cassetta, A.; Fabrizi, G.; Parisi, L. M. Synlett 2001, 1605-1607. doi:10.1055/s-2001-17458

20. Cacchi, S.; Marinelli, F. In Organopalladium chemistry for Organic Synthesis; Neghishi, E.; de Meijere, A., Eds.; John Wiley \& Sons: New York, 2002; Vol. 2, pp 2227-2244.

21. Battistuzzi, G.; Cacchi, S.; Fabrizi, G. Eur. J. Org. Chem. 2002, 2671-2681. doi:10.1002/1099-0690(200208)2002:16<2671::AID-EJOC2671>3.0.C $0 ; 2-X$ See for a review.

22. Xu, M.; Xu, K.; Wang, S.; Yao, Z.-J. Tetrahedron Lett. 2013, 54, 4675-4678. doi:10.1016/j.tetlet.2013.06.079

23. Arcadi, A.; Cacchi, S.; Fabrizi, G.; Ghirga, F.; Goggiamani, A.; lazzetti, A.; Marinelli, F. Synthesis 2018, 1133-1140. doi:10.1055/s-0036-1589158

24. Arcadi, A.; Cacchi, S.; Fabrizi, G.; Goggiamani, A.; lazzetti, A.; Marinelli, F. Org. Biomol. Chem. 2013, 11, 545-548. doi:10.1039/C2OB27125G

25. Cacchi, S.; Fabrizi, G.; Pace, P.; Marinelli, F. Synlett 1999, 620-622. doi:10.1055/s-1999-2659

26. Kidjemet, D. Synlett 2002, 1741-1742. doi:10.1055/s-2002-34251

27. Nathubhai, A.; Patterson, R.; Woodman, T. J.; Sharp, H. E. C.; Chui, M. T. Y.; Chung, H. H. K.; Lau, S. W. S.; Zheng, J.; Lloyd, M. D.; Thompson, A. S.; Threadgill, M. D. Org. Biomol. Chem. 2011, 9, 6089-6099. doi:10.1039/c1ob05430a

28. The use of a lower excess of DMFDMA decreased the yields of products.

29. Utimoto, K.; Miwa, H.; Nozaki, H. Tetrahedron Lett. 1981, 22 , 4277-4278. doi:10.1016/S0040-4039(01)82932-4

30. Iritani, K.; Matsubara, S.; Utimoto, K. Tetrahedron Lett. 1988, 29 1799-1802. doi:10.1016/S0040-4039(00)82047-X

31. Arcadi, A.; Cacchi, S.; Fabrizi, G.; Marinelli, F.; Parisi, L. M. Heterocycles 2004, 64, 475-482. doi:10.3987/COM-04-S(P)23

32. Abbiati, G.; Arcadi, A.; Chiarini, M.; Marinelli, F.; Pietropaolo, E.; Rossi, E. Org. Biomol. Chem. 2012, 10, 7801-7808. doi:10.1039/c2ob26380g 


\section{License and Terms}

This is an Open Access article under the terms of the Creative Commons Attribution License

(http://creativecommons.org/licenses/by/4.0). Please note that the reuse, redistribution and reproduction in particular requires that the authors and source are credited.

The license is subject to the Beilstein Journal of Organic Chemistry terms and conditions:

(https://www.beilstein-journals.org/bjoc)

The definitive version of this article is the electronic one which can be found at:

doi:10.3762/bjoc. 14.218 